\title{
MEUS DOCUMENTOS, NÃO! UMA REFLEXÃO SOBRE A MUDANÇA NAS NARRATIVAS SOBRE A DITADURA MILITAR BRASILEIRA E UM CONVITE AO ESFORÇO INDIVIDUAL DE LEMBRAR
}

\author{
NOT MY DOCUMENTS! A REFLECTION ON THE CHANGE IN THE \\ NARRATIVES CORCERNING THE BRAZILIAN MILITARY DICTATORSHIP \\ AND AN INVITE TO THE INDIVIDUAL EFFORT OF REMEMBERING
}

Heloisa Pait*

\section{Um armário profundo}

E então me mudei para um antigo apartamento, de pé direito de 3 metros, com armários profundos, um deles invadindo a cozinha em "L" de tal modo que se poderia guardar apenas naquele canto inalcançável um metro cúbico inteiro de tralhas.

Foi exatamente naquele lugar, imagino, que meu pai não enfiou as armas que lhe pediram para guardar por uns dias, nos anos de chumbo da ditadura brasileira. Ali ficaram apenas malas de viagem, projetos de meu pai e material de ensino de minha mãe. Ou então roupas e brinquedos que iam se acumulando numa casa de quatro pessoas mais a empregada. Pois os anos eram de chumbo, mas a vida continuava produzindo o entulho que lhe é testemunho.

Não sei quem pediu, nem exatamente quando. 1969, 1970? Não sei. Em algum ano, alguém pediu, disse meu pai quando lhe perguntei o que havia feito na ditadura. Nem sei mesmo o que foi que pediram para guardar: armas mesmo, ou uma mala que poderia ter armas? Só sei que meu pai recusou, e a vida seguiu em frente.

Agora volto a esse apartamento onde nasci, presente de meu avô a seu genro, um dote. E, nas rememorações dos 50 anos do Golpe Militar no Brasil, olho para o alto, em direção àquele canto de armário, como se de fato houvesse algo lá dentro que os sucessivos inquilinos nunca conseguiram tocar, de tão fundo.

\section{Narrativas em trânsito}

E o que é que seria, essa coisa intangível? Quem é que poderia me dizer? Como fazer uma pergunta de pesquisa que uma agência de fomento apoiasse - que mala meu pai nunca chegou a guardar em sua casa?

Acredito que busquei essa mala nos recentes eventos organizados para relembrar o golpe de Estado de 1964 no Brasil, golpe esse a quem cada um dá um nome distinto. "A redentora", dizia o jornalista Sergio Porto. Minha mãe falava em "gloriosa", talvez

\footnotetext{
* Professora de sociologia da UNESP de Marília. E-mail: <heloisa.pait@ fulbrightmail.org>
} 
parafraseando outro humorista. A revolução. $1^{\circ}$ de abril ou 31 de março. A ditadura. O regime militar. A cada evento, eu parecia mais distante do buraco no meio das tralhas onde a mala poderia ter ficado.

As narrativas apresentadas hoje, nesses eventos comemorativos, são certeiras, corretas, indubitáveis. Por exemplo, elas dizem que foram os Estados Unidos, ponto. Os Estados Unidos, vejam só os documentos! Não o país que eu e você conhecemos, cheio de interesses contraditórios, organismos do Estado e da sociedade civil com modos de agir e objetivos distintos e a imprensa dando ressonância a isso tudo. Um ente único, manobrando governos à revelia de suas populações indefesas e principalmente nos eximindo como cidadãos, herdeiros das instituições, de qualquer responsabilidade. Como os americanos guardam e depois publicam seus documentos, de fato há mais registros sobre suas ações do que sobre as nossas, que mofam dispersos.

$\mathrm{Na}$ narrativa que aprendi na faculdade, logo após a democratização, os heróis eram senhores de cabelos brancos e gravata, fala empolada e barriga proeminente, e uma estranha coragem de falar em público que incomodava o regime. O grande herói era Ulysses Guimarães, político profissional e articulador da campanha pelas Diretas Já de 1983-84, mas também outros: escritores de novela de televisão que embutiam críticas ao regime, jornalistas que encontravam jeito de burlar a censura, militares que conseguiram domar a máquina da repressão, economistas que denunciaram a piora na concentração de renda, feministas e artistas da contra-cultura que traziam outros assuntos para a conversa chata da ditadura moralista.

A luta armada era vista na segunda metade dos anos 1980 como algo equivocado que atrasou a transição. Não me recordo de recriminações maiores, de alguém dizer que os guerrilheiros eram financiados por governos totalitários e que não eram parte do campo democrático. Ou isso era óbvio para os meus professores, ou não se queria tocar no assunto, ou - era a minha impressão - não se via nesse período a luta armada como algo consistente, que poderia ter mudado o país. Eu me recordo dos mais velhos dizendo que ninguém imaginava que os guerrilheiros fossem tão poucos.

\section{Uma outra São Paulo}

A luta armada brasileira não estava ligada, como na França ocupada, a toda uma rede de pessoas, associações, publicações, que executavam ações variadas e contavam com apoio externo. Não se tratava no Brasil de uma sociedade paralela à oficial, e sim de algumas pessoas muito combativas contando com apoio bastante restrito da sociedade como um todo. A maior parte das ações, me parece pelos relatos, se assemelhava aos crimes comuns que enfrentamos todos os dias nas grandes metrópoles brasileiras, com a exceção de poucas ações mais violentas, do sequestro do embaixador americano e da guerrilha do Araguaia.

A parte, digamos, civil da resistência deu-se de modo frágil, por conta de prisões, assassinatos, exílios, demissões, cassações e censura, além do medo que tudo isso causa em qualquer um para falar e agir. Mas ela estava mais conectada à sociedade aberta que à clandestina: dava-se nos partidos políticos, nas associações profissionais, no debate acadêmico e principalmente na esfera cultural. Um mundo paralelo inteiro, como foi possível 
construir sob alguns governos totalitários, não existiu no Brasil sob o regime militar; a resistência era parte da vida comum.

“A gente sabia o que estava acontecendo. Às vezes você via os policiais na rua, depois de um confronto, ou alguém contava que um aparelho havia sido estourado", disse meu pai. "Ouviam os gritos da Rua Tutóia", ele disse também, se referindo a um centro de torturas no bairro do Paraíso. O país do início dos anos 1970 não era o colosso que é hoje. As cidades, muito menores. Causa uma certa estranheza ler sobre os endereços onde os confrontos urbanos se deram, pois são parte hoje de um centro muito circunscrito, uma cidade que se percorre a pé: a Rua Barão de Capanema, onde Boilsen foi assassinado, a Alameda Casa Branca, onde Marighella foi morto. O cruzamento aqui do lado da Rua da Consolação com o Maria Antônia, onde um automóvel explodiu.

No início dos anos 1970 não havia nem telefones públicos nas ruas, e pelo que entendi os que havia, em bares, não recebiam chamada. O modo arriscado de comunicação dos guerrilheiros, através de encontros previamente marcados, nos quais muitos foram presos ou mortos, vinha dessa falta de alternativas. É preciso mesmo voltar atrás para entender o período, e não apenas no que diz respeito à política nacional e internacional ou ao contexto cultural e ideológico. É preciso também imaginar uma outra São Paulo, um outro espaço urbano onde as pessoas se movimentavam e se comunicavam de outros modos.

\section{Aprendendo a ditadura}

Esse ensaio é sobre a memória daquele período, sobre uma memória que se altera, que se reescreve. Ao final dos anos 1980, eram os moderados de lado a lado que haviam feito a transição democrática: os cientistas políticos elaboravam seus modelos de transição a partir daí. Havia insatisfações concretas, que se expressavam de modo mais ou menos aberto. Havia a necessidade de abertura por parte do próprio regime, cada vez mais sugado pela corrupção e ineficiência da máquina estatal.

Uma história que testemunhei foi a epidemia de meningite, causada pela falta de planejamento da urbanização do milagre e cujas notícias foram censuradas pelo regime até 1975. Minha mãe, quando soube, foi até o consulado francês para vacinar a nós, seus filhos, e a mais dois colegas nossos. Vi, olhando para o alto, aquela mulher falando uma língua estrangeira, retrucando com o cônsul até que ele, exausto e mau-humorado, nos levou para tomar as vacinas reservadas aos cidadãos franceses. Só que na pressa, ele pegou a mim e a nosso amigo também ruivo; meu irmão e o outro menino viriam para tomar a vacina outro dia! Foi uma meia vitória.

Minha mãe ficou uma fera com o regime. Provavelmente foi a partir daí que ela começou a se referir aos militares no poder como "milicos filhos-da-puta", expressão corriqueira em casa, usada para todos os governantes que botavam o regime à frente do bem estar da população. Provavelmente foi aí também que muitas outras mulheres, com ou sem cara de pau para entrar num consultado exigindo vacinas, passaram a votar na oposição.

$\mathrm{Na}$ história que aprendi na faculdade, insatisfações populares como essa haviam dado leverage aos negociadores da oposição que, dando garantias aos militares, foram obtendo concessões cada vez maiores, como a Lei de Anistia, já em 1979, e o afrouxamento da 
censura. Não sei se era uma narrativa completa, ou 100\% correta. Qual foi o papel dos Estados Unidos na ditadura? Qual exatamente foi o acerto da oposição com os militares? Como morreu JK? Mas era uma narrativa calcada na análise social e econômica objetiva, no confiança no poder do diálogo e da busca de objetivos comuns, e na capacidade política de cidadãos organizados abertamente. Era uma narrativa democrática e, acredito hoje ainda, fundamentalmente correta.

Nas narrativas atuais os desenhistas da transição saíram de cena. Veja a recente exposição na Estação Pinacoteca em São Paulo, no prédio que abrigou o DOPS, a antiga polícia política estadual, que lembra a atuação dos advogados resistentes. Senti falta na exposição de referências a dois nomes importantes da luta contra a ditadura no Brasil: José Gregori, que lutou pela Lei da Anistia, e Raymundo Faoro, que colocou a Ordem dos advogados do Brasil na linha de frente contra o regime, exigindo o "fim do arbítrio", palavra de ordem do movimento pela redemocratização. A Lei de Anistia, de 1979, permitiu que centenas de brasileiros voltassem ao seu país, muitos dos quais retomando carreiras políticas interrompidas pelo exílio. O fim do arbítrio é algo pelo que ainda temos que lutar, pois é fato que nossa polícia sempre foi e ainda é violenta, nossas leis nunca coibiram e não coíbem o roubo dos cofres públicos. Por que riscar da memória a conquista da Lei de Anistia e a luta pelo fim do arbítrio?

A idéia hoje é que a transição foi "incompleta", inclusive no discurso acadêmico. O que seria uma transição completa, e de acordo com quem? Se vivemos hoje numa sociedade democrática, e vivíamos sob regime autoritário, em que esfera se dá essa incompletude? Seria equivalente a dizer que duas pessoas antes solteiras e hoje casadas não tiveram um casamento completo.

A Comissão da Verdade instituída em 2012 tem um foco muito definido, de apuração das graves violações dos direitos humanos cometidos pelo Estado especialmente durante a vigência do regime militar. Esse foco é importante para que os trabalhos possam se desenvolver e não se percam em crimes já investigados ou sem a mesma gravidade, muito mais numerosos. Foi isso que permitiu que se descobrisse o destino de algumas vítimas da repressão, mesmo com todas as dificuldades existentes: a falta de documentos, a hesitação das Forças Armadas e o próprio tempo transcorrido. Os holofotes se voltaram aos porões da ditadura, aos centros de tortura em locais oficiais e clandestinos. Para quem conhece a história, esse novo conhecimento, fundamental, direito das famílias, das vítimas e do país, se agrega ao que já sabíamos. Para as novas gerações, a impressão que se têm é que a luta pela democratização foi feita entre agentes da repressão e guerrilheiros.

Quantos brasileiros hoje viveram o período autoritário? Quantos podem perguntar aos pais sobre o que era viver sob censura? Nos anos 1970, milhares de brasileiros fugiam de lugares onde o poder local era tão opressivo que valia a pena tentar a vida em grandes cidades do Sul. Em São Paulo, a sobrevivência diária e a busca de oportunidades num ambiente anônimo davam o tom. Esses brasileiros falam apenas dessa outra luta aos seus filhos e netos: a busca diária pelo emprego, pela moradia e pelo reconhecimento como ser humano na "selva de pedra". Resistir - ou aderir - à ditadura eram termos que não faziam parte do vocabulário desses milhares de migrantes. É nesse contexto social que a atenção do debate nacional à 
guerrilha e à repressão se dá. Para muitos brasileiros, a primeira aula sobre a ditadura não foi o fechamento do Centro Acadêmico, a mãe implorando uma vacina, ou o relato de um pai sobre um comício das Diretas Já. A primeira aula está sendo sobre torturadores e guerrilheiros. São eles os protagonistas da nova narrativa.

Nos jornais eu leio hoje nomes que não vou reproduzir aqui, nomes malditos de quem até mesmo o Exército ostracizou. Também leio depoimentos de pais de amigos meus. Parece que a grande luta foi feita nesse embate, em tiroteios pela cidade e na selva e nas sevícias nos porões: quem resistiu, que falou. Parece que a democracia brasileira resultou desse embate violento. Quase que numa narrativa religiosa, o país emerge do sofrimento indizível dos jovens guerrilheiros. E talvez haja mesmo algo religioso nisso, a busca de mitos nacionais agora que a religião brasileira está mais plural, carente de uma mitologia comum. Essa é a nova narrativa: a mudança social resulta da fé inabalável nas próprias idéias, da capacidade de botar o outro na linha de frente e, finalmente, do martírio.

\section{Generais na TV}

Outra história que meu pai contou dizia respeito ao final dos anos 1960, ainda antes do AI-5, quando houve os conflitos entre estudantes na Rua Maria Antônia. Ele, professor da Escola de Arquitetura do Instituto Mackenzie, muito conservador, foi pedir à reitora que interviesse junto aos alunos para acalmar os ânimos. "Pode haver uma tragédia ali", ele disse à reitora, junto com outros professores. Ela ignorou os apelos. Pelo que meu pai contava, professores de esquerda do outro lado da rua faziam o contrário: incitavam os jovens aos protestos. Lembro de meu pai olhando para baixo, balançando negativamente a cabeça, e depois dizendo: "Não eram só brigas de rua; alguns anos depois viria a guerrilha e aqueles jovens perderiam a vida."

\section{E seu meu pai tivesse guardado a mala?}

Minha mãe tinha desprezo pelos "milicos", mas meu pai tinha ódio aos generais. O presidente Geisel era "aquele desgraçado que falava alemão com o Gerdau no Palácio do Planalto!" $O$ ato descrito equivalia a vilipendiar a nação, enterrar quaisquer sonho de um Brasil progressista que Juscelino ou Niemeyer tiveram quando conceberam o prédio que abriga a presidência da República. Testemunhei esse ódio em 1975, quando Geisel instituiu um depósito compulsório para quem fosse viajar ao exterior, às vésperas de nossa viagem aos Estados Unidos, que meu pai cancelou. Para ele, não foi um imposto ilegal apenas. Era como se Geisel ele mesmo tivesse dito ao meu pai ali em casa e não através da Rede Globo: se você trabalhou a vida inteira ou não não vem ao caso; cala a boca pois não vai ser dessa vez a sua viagenzinha com a família. Só vi tamanho ódio anos depois, na casa de cubanos quando Fidel aparecia na televisão.

Daquela época, lembro do Cid Moreira, em plantões de notícias ou no Jornal Nacional, relatando com um gravidade que hoje seria patética os desmandos do governo, o pacote de Abril. Já havia um certo ridículo na coisa, uma exasperação dos espectadores mais que o medo, os anos de chumbo já haviam acabado, ou não?

Meu irmão se lembra vagamente da morte de Herzog, logo em seguida ao depósito compulsório; eu apenas lembro do modo como minha mãe se referiria pela vida toda ao 
Rabino Sobel, que não aceitou a versão oficial de suicídio do jornalista. Minha mãe não tinha mente política; para ela, os atos humanos se dividiam simplesmente em certos e errados, e parecia a ela que Sobel tinha feito a coisa certa naquele momento.

Uma vez, um policial parou minha mãe e resolveu apreender o carro e os documentos dela. Minha mãe deu um golpe no pulso do policial e tirou os documentos dela da mão dele. Não era algo muito recomendado para se fazer na época: "O carro o senhor apreende; meus documentos, não." Meu pai teve que ir à delegacia retirar o carro, pois isso ainda era coisa de homem. Eu mesma, adulta, ainda peguei uma época em que mulher não entrava em delegacia ou oficina mecânica sozinha. Não deve ter sido confortável. O que exatamente os serviços de segurança sabiam sobre cada brasileiro? Não havia como saber.

Mas é o Brasil, e o leitor deve ter em mente as idéias Sergio Buarque de Holanda, Roberto DaMatta e outros. Meu pai era tenente da reserva, por ter feito o serviço militar no CPOR, um núcleo de formação de oficiais. Então provavelmente na delegacia, naquele dia, não era o ex-comunista ídish que se apresentava, mas o Tenente Henrique Pait, oficial da reserva do Exército Brasileiro. E tudo correu bem.

Para minha mãe, Sobel havia feito algo semelhante: o carro o senhor apreende; meus documentos, não. $\mathrm{O}$ assassinato de Herzog poderia ter sido uma inflexão na transição; dali poderia ter havido um novo AI-5 ou a emergência de conflitos abertos dentro do próprio regime arrastando o país. No final, todos sabemos, aquela tragédia acabou apertando o passo da abertura.

A partir daí, houve a reorganização da sociedade civil, com cautela por causa dos grupos militares linha-dura ainda atuantes e perigosos. Desta época, já tenho memória bem clara. Na minha escola, em 1978, uma escola de classe alta no bairro do Pacaembu, votavam todos na Arena, o partido de sustentação do regime militar, criado artificialmente por uma lei eleitoral que acabou com os partidos de então. Todos menos eu e a Patrícia Masiero, na $4^{\mathrm{a}}$ série do curso primário. Cantávamos: Emi-Dê-Bê, Oba! Emi-Dê-Bê, Oba! Nossos colegas respondiam: Aareeenaa, Aareeenaa! Nosso jingle era mais animado, mas éramos só duas. Não entendo como nossos professores deixavam aquilo, mas deixavam, e um ano antes da aprovação da Lei de Anistia, as crianças já opinavam livremente sobre seus partidos favoritos.

\section{Alinhavando estórias}

No saguão do Congresso Nacional, que teve momentos gloriosos e vergonhosos em sua relação com o regime militar, uma exposição muito bem feita lembra da tortura e dos desaparecidos nesses 50 anos do golpe. Mas quem aderiu ao golpe dentro daquele prédio? Que razões tinha? Quem resistiu da tribuna da Câmara dos Deputados? E que preço foi pago? Caramba, quem votou contra a emenda Dante de Oliveira? Não era assunto da exposição. Cinicamente, podemos ver aí um modo de se adaptar aos novos tempos, pois hoje quem está no poder é o PT de José Genoíno e não o MDB de Tancredo Neves. E talvez meu artigo todo possa se resumir nisso: os tempos mudam, mudam as histórias. É preciso, como em 1964, em 1968, em 1979, em 1984, adaptar-se camaleonicamente ao que o momento exige, e hoje a exigência é lembrar da luta armada como elemento central da resistência à ditadura. Mas é mais que isso. 
Essas narrativas novas são mais fáceis de endossar do que enfiar a cara nos armários sujos, mofados, empoeirados de nossas próprias casas e ver o que ainda há lá. Qual foi o papel da universidade nos anos de chumbo? Com muita hesitação as burocracias corrigem seus erros, e com muito pouco alarde. É fácil para os intelectuais apenas ironizarem o reconhecimento público do erro da Rede Globo em apoiar o golpe de 1964: reconhecer os próprios erros implica aceitar a hipótese de que hoje também vozes incômodas são silenciadas. O próprio Exército, de que modo lida com seu passado? Eu queria ver as Forças Armadas iniciando um diálogo interno sobre os expurgos que fizeram em suas instituições e sobre seu papel na violência de Estado. Queria ver as celebrações de 31 de março se transmutando em reflexões e um pedido de desculpas emergindo em consequência delas.

Quem melhor resumiu o estado das coisas do debate nacional foi um líder da comunidade judaica que encontrei, no lançamento de um livro sobre o papel dos judeus na construção da democracia no Brasil. "Não, não vai ter debate. Debater o quê? É o que aconteceu. É só o lançamento de um livro." Algo muito incoerente havia ali, um judeu dizendo que não há o que debater, sobre um assunto que poderia deixar até o mais contemplativo dos povos falando por décadas. Que fizemos? Resistimos? Nos calamos? Lutamos? E por quê? Se pegamos em armas, podíamos ter feito isso sem, como disse minha mãe, entregar os documentos pessoais, sem nos perder de quem somos? E se não pegamos, pecamos por omissão? O livro, que tinha poucos artigos bons, não convidava à reflexão, não trepava no maleiro empoeirado - ele reprisava eventos icônicos da vida judaica no Brasil durante a ditadura. Podíamos ter feito mais? Deveríamos ter feito menos? Para um pequena comunidade, me parece que fizemos o suficiente, mas esse é um debate que deveria tocar em tudo e em todos, especialmente nos jovens, pois é a história deles de que falamos, é a sua herança. $\mathrm{O}$ organizador do evento arrematou: "As pessoas que conversem umas com as outras", ele disse, apontando o espaço amplo e decrépito onde o evento se deu, no que aliás ele estava coberto de razão.

Como tudo que importa no Brasil, esse resgate da memória não será feito em eventos chapa-branca, em cerimônias oficiais, que servem de modo geral a interesses corporativos, à afirmação de identidades fixas com ligação tênue com a nação. São as conversas paralelas, seguidas de pedidos para que não se leve à público, as confissões feitas numa carona imprevista, as palavras ainda caladas, que contam. Elas podem ser disparadas pelos eventos oficiais, mas não são esses que construirão uma memória nacional verdadeira. Principalmente, não serão esses discursos que vão elaborar uma narrativa cívica, que sirva para todos os brasileiros, independente de suas posições políticas ou das ações de seus pais.

Essa narrativa cívica não precisa ser anódina ou relativista. Ela pode apontar culpados, ela pode assumir erros. Mas ela precisa enxergar a todos como cidadãos imersos em suas instituições, muitas dos quais embarcariam numa nova aventura autoritária sem hesitações. Essa narrativa privilegiaria os elementos dissonantes. $\mathrm{O}$ médico que publica diligentemente os diagnósticos de uma epidemia. O coronel que pede transferência quando uma freira é trazida para o interrogatório. $\mathrm{O}$ empresário que diz não às negociatas dos militares. $\mathrm{O}$ guerrilheiro que sustenta que a luta acabou. O diplomata que busca diálogo entre países. E mesmo um rabino estrangeiro, que de fato fez algo admirável, antes ainda da presidência de Carter. Essa narrativa privilegiaria decisões que nós, no futuro, podemos precisar tomar nós mesmos, 
talvez contra a corrente, na defesa da democracia brasileira. E apontaria que características tinham as instituições que mais facilmente se livraram dos seus e aderiram ao status quo.

A internet, essa coisa ainda meio mágica, pode ajudar nesse diálogo extra-oficial, digamos. Sem grandes pesquisas ou financiamentos, bastando uma boa conexão de internet e pouca paciência, qualquer um pode ver hoje o documentário sobre o cantor Wilson Simonal, que se assumiu como delator do regime e por ter se assumido, mais que por ter sido, nunca foi perdoado. Quem quiser pode ler o manual de guerrilha de Marighella ou os diários de Grabois no Araguaia, que falam por si sobre como pensavam e o que queriam os guerrilheiros em nome dos elementos da massa. Filtrada pelo desrespeito à democracia e aos direitos humanos, também se pode ler a história semi-oficial contada pelos militares e por desprezíveis agentes da repressão. Entrevistas com exilados, memórias de apoiadores da guerrilha, filmes sobre eventos específicos, imagens de TV da Campanha das Diretas, a longa ditadura tem muitos personagens e fatos que não cabem em narrativas pré-fabricadas.

Ao final dessa conversa feita nas linhas e nas entrelinhas, nos livros e sussurros, alguns pediriam perdão, outros acusariam, mas fundamentalmente todos nós, como brasileiros, choraríamos uma grande oportunidade perdida. A de termos feito a gigantesca transição de um país agrário a um país industrial sob uma democracia, que seria um exemplo para a América Latina e para o mundo, que seria, esse país sim, um Brasil Grande! Um lamento coletivo, um dia de tristeza compartilhada, esse novo 31 de março que eu imagino.

E, claro, cada um se inseriria de um modo nesse emaranhado de histórias, imaginando o que teria feito, onde e como. Cada um buscaria um herói, um ponto de apoio, um norte nessa guerrilha maior que não era contra uma ditadura apenas, mas contra um inimigo que nós, como nação, não soubemos identificar no momento. Eu, claro, é óbvio pelo meu relato, já tenho o meu herói, meu documento, meu pai. 